\title{
A constituição humana na linguagem: um olhar para o homem e sua relação com os esquemas culturais
}

\author{
Marlete Sandra Diedrich ${ }^{1}$ \\ Curso de Letras, Universidade de Passo Fundo, Passo Fundo, RS, Brasil
}

\begin{abstract}
Resumo: Este artigo se ocupa da noção de esquemas culturais mobilizados pela língua no seio da vida social. Tem por objetivo discutir, a partir dessa noção, a realização da propriedade de significância da língua em sua relação com o homem na sociedade. Para tanto, baseia-se na tríade homem-linguagem-cultura, a partir da qual se constitui a natureza antropológica da linguagem. O homem inventa e compreende símbolos de tal forma que se estabelece um elo entre viver e significar. Assim, a língua no discurso revela o uso particular que os homens fazem da língua a partir de determinados direcionamentos, os quais definem, em parte, os modos de enunciar. Isso é possível porque a vida social e cultural se imprime na língua a partir dos esquemas vivenciados no deslocamento do homem em sua vivência marcada pela linguagem, os quais constituem a historicidade humana na linguagem.
\end{abstract}

Palavras-chave: Esquemas culturais; Significância; Historicidade.

Title: Human constitution in language: a look at man and his relationship with cultural schemes

Abstract: This article deals with the concept of cultural schemes mobilized by the language on social life. It has as goal to discuss, from this perspective, the fulfillment of language significance property in its connection to man and society. Man reinvents and comprehends symbols in such a way that a link is established between living and meaning. Therefore, the language in the speech reveals the particular use that men make from language from certain directions, which partly defines the ways to enunciate. This is possible because the social and cultural lives are in the language, from the schemes experienced in the dislocation of man and his experience marked by language, which constitute the human historicity in language.

Keywords: Cultural schemes; Significance; Historicity.

\section{Uma breve contextualização}

A reflexão apresentada neste artigo se ocupa da seguinte temática: a noção de esquemas culturais mobilizados pela língua no discurso, o que acontece no seio da vida social. Esta temática é derivada da leitura que fazemos da obra do linguista Émile Benveniste, motivada, principalmente pela seguinte afirmação do autor:

\footnotetext{
${ }^{1}$ Doutorado (Universidade Federal do Rio Grande do Sul). Professora da Universidade de Passo Fundo. Orcid: https://orcid.org/0000-0002-9177-089X.E-mail: marlete@upf.br.
} 
Do mesmo modo que não falamos aleatoriamente, quero dizer sem quadros, que nós não produzimos a língua fora de certos quadros, de certos esquemas que possuímos, do mesmo modo creio que a arte não se produz também fora de quadros ou esquemas diferentes mas que também existem. (BENVENISTE, 1989, p. 27-28)

Deixemos claro, desde já, que não encontramos nos estudos benvenistianos uma definição explícita do que o autor entende por "quadros" ou "esquemas", mas, a partir de princípios propostos pelo linguista em questão, buscamos definir alguns elementos que possam nos auxiliar a melhor entender o que Benveniste propõe com esta noção e de que forma ela ajuda a compor o que estamos entendendo aqui como antropologia da enunciação. Nosso objetivo neste artigo é discutir, a partir da noção de esquemas culturais, a realização da propriedade de significância da língua em sua relação com o homem na sociedade e na cultura.

É possível afirmar que essa reflexão se insere num eixo de estudos compreendido como aquele que busca nas interpretações da teoria da linguagem de Benveniste a possibilidade de prospecção teórica. Isso porque, pautados numa visão antropológica da linguagem, acreditamos ser possível iluminar a discussão sobre a tríade homem-linguagemcultura a partir dos princípios advindos dos estudos benvenistianos. Assim, uma investigação por essa tríade se justifica na medida em que coloca em destaque a existência do homem na sociedade, o que se dá por via da linguagem. Para tanto, apoiamo-nos em Dessons (2006, p. 6), pois, para o autor, a indissociabilidade entre o homem e a linguagem permite pensar numa "antropologia da linguagem, na qual o que se sabe da linguagem aparece indissociável do que se sabe do homem, os dois saberes se implicando reciprocamente" (DESSONS, 2006, p. 6).

Flores (2018, p. 36) vê nessa antropologia da linguagem, concebida por Dessons (2006), uma antropologia da enunciação: “A antropologia da enunciação, nesses termos, é apresentada como o estudo do saber do homem que advém da sua capacidade de enunciar". A partir dos estudos de Flores no Brasil, essa visão tem possibilitado incursões científicas importantes representadas por um significativo número de teses produzidas e artigos científicos publicados, trabalhos que consolidam esse modo de ver a enunciação e o próprio homem em sua experiência de linguagem. Exemplo disso é o que afirma Neumann (2016, p. 164) acerca do discurso: "o discurso se torna então o lugar por onde a língua e o homem brotam e nascem a cada ato enunciativo, através do processo de historicização".

Sendo assim, definimos para nossa explanação um percurso pautado, inicialmente, na tríade homem-linguagem-cultura, uma vez que há valores culturais impressos na língua, tal qual afirma Benveniste (1989); ao mesmo tempo em que reconhecemos que esses valores se dão a conhecer na vida em sociedade, por meio da relação semiológica entre língua e sociedade, já que a língua contém os valores culturais de uma sociedade em particular. Com os princípios mobilizados neste percurso, chegamos à discussão específica da noção de esquemas culturais, nosso tema central neste artigo, a qual buscamos ilustrar com uma manifestação discursiva singular expressa no modo como a língua se comporta na vivência do literário, entendido aqui também como um modo de enunciar. 


\section{Homem-linguagem-cultura}

A aventura do homem na linguagem só é possível porque o homem inventa e compreende os símbolos. É justamente a partir dessa capacidade de inventar e compreender a língua no discurso que vemos se concretizar a tríade homem-linguagem-cultura: é a realização de significância na língua manifestada em sua relação com o homem na sociedade. Dessons (2006) se ocupa da questão da significação, lembrando que tal questão em Benveniste é central, uma vez que a linguagem tem por função dizer alguma coisa, logo, o estudo do sentido na língua não se dissocia do estudo do sentido na linguagem. É a faculdade significante da linguagem que constitui seu caráter principal e explica todas as funções no meio humano relacionadas às realizações individuais e coletivas que se dão no exercício do discurso; tais realizações representam, no fim das contas, o conjunto das experiências humanas. Segundo este raciocínio, a relação circular que se estabelece entre o ato de viver e o de significar define a natureza irredutivelmente antropológica da linguagem, numa íntima relação entre vida e sentido. Nessa relação, encontra-se implicada a capacidade de simbolizar, de representar o mundo, uma capacidade inerente ao ser humano. É importante lembrar que "representar", nesta perspectiva, não se trata de um espelhamento do mundo, mas, conforme atestado por Dessons (2006) e por tantos outros que trabalham na perspectiva enunciativa, o prefixo re-marca, nos estudos benvenistianos, um duplo valor, a saber: por um lado, refere a iteração, ou seja, o que acontece novamente; de outro lado, refere a ideia de invenção, de novidade. É com essa potência de sentido que a ideia de representar o mundo deve ser entendida, o que implica assumir uma postura teórico-metodológica frente aos fatos de linguagem que dê conta da relação entre esses dois sentidos implicados no ato de viver e de significar e que acabam por definir o próprio homem, como veremos no decorrer desta reflexão.

Em Estruturalismo e linguística (1989, p. 20-21), ao ser indagado sobre a semiologia na perspectiva saussuriana, Benveniste acaba desenvolvendo a ideia segundo a qual "a apropriação da linguagem é a apropriação do conjunto de dados que se considera que ela traduz, a apropriação da língua por todas as conquistas intelectuais que o manejo da língua permite". Diz isso para, em seguida, desenvolver a ideia do semiótico e do semântico, a qual é apresentada da seguinte forma: é semiótico tudo que está relacionado a ser reconhecido ou não no interior da língua; já o semântico está relacionado à circunstância, à abertura para o mundo. $\mathrm{O}$ autor afirma que esta ideia precisa ser melhor delineada, mas que certamente este modo de pensar o leva à cultura. Em função dessa certeza, ele diz: "Tudo o que é do domínio da cultura deriva no fundo de valores, de sistemas de valores. Da articulação entre os valores. Muito bem! Estes valores se imprimem na língua." (1989, p. 22). O destaque dado à noção de valores culturais impressos na língua é fundamental em nossa reflexão, pois, com ela, somos levados a pensar que, de fato, a vida se desenvolve a partir de sistemas de valores culturais articulados, organizados, realidade que nos autorizamos a relacionar com a noção de esquemas culturais que se dão a conhecer na mobilização da língua no discurso. 
Na sequência de sua entrevista, ao discutir o fato de que a língua não se sustenta na natureza, mas na cultura, uma vez que o homem nasce na cultura, o autor afirma:

Vemos sempre a linguagem no seio da sociedade, no seio de uma cultura. E se digo que o homem não nasce na natureza, mas na cultura, é que toda criança e em todas as épocas, na pré-história a mais recuada como hoje, aprende, necessariamente com a língua os rudimentos de uma cultura. (BENVENISTE, 1989, p. 23)

Essa afirmação é fundamental para entendermos a relação proposta pelo autor entre língua e cultura: uma não existe sem a outra, aliás, é muito mais do que isso: uma se define na e pela outra.

Nessa linha de raciocínio, o autor chega ao mecanismo de significação a partir do poder simbólico da língua, uma vez que todo o mecanismo da cultura é um mecanismo de caráter simbólico, cujos valores encontram-se organizados, hierarquizados em modelos. Com esse olhar, o linguista justifica o papel da linguística junto às demais ciências humanas, na busca de compreensão do "fundo comum" (BENVENISTE, 1989, p. 27) do homem. E, a partir daí, segundo o autor, reencontramos o problema que a língua nos ensinou a ver e que já apresentamos na contextualização deste artigo, mas que, mesmo assim, dada sua importância, repetimos, lembrando, inclusive, da dupla significação do prefixo re também no verbo repetir:

Do mesmo modo que não falamos aleatoriamente, quero dizer sem quadros, que nós não produzimos a língua fora de certos quadros, de certos esquemas que possuímos, do mesmo modo creio que a arte não se produz também fora de quadros ou esquemas diferentes mas que também existem. E que são alterados ou que renascem na medida mesmo em que se toma consciência do que prescreveu. (BENVENISTE, 1989, p. 27-28).

Destacamos, desta reflexão de Benveniste, a ideia de "fundo comum do homem", que se manifesta na língua e nas artes em geral, sempre a partir de determinados quadros ou esquemas. Acreditamos que esta relação nos permite pensar na relação entre língua e os valores culturais de uma sociedade, os quais se manifestam em determinados esquemas, e que caracterizam sempre uma relação semiológica. Há de se destacar ainda na citação anterior dois outros elementos: a ideia de que há uma tomada de consciência acerca desses quadros, a qual possibilita a alteração ou renovação de tais elementos; e a relação com a arte, o que nos leva a ilustrar a noção de esquemas culturais justamente com a expressão literária, poética, ou seja, a língua em seu estado artístico.

Essas considerações nos levam a outro texto do autor, contemporâneo ao Estruturalismo e linguística; trata-se de Estrutura da língua e estrutura da sociedade (1989), no qual o autor afirma que há uma função mediadora do símbolo entre o homem e o mundo. Essa aventura humana de mediação se dá na e pela cultura, o conjunto dos valores de uma comunidade humana. No centro da cultura, a língua aparece como atividade significante por excelência, uma vez que a significação não é alguma coisa que lhe é dado por acréscimo, mas é ela mesma. 
Essa constatação permite que Benveniste (1989, p. 99) chame a língua "de máquina de produzir sentido". E o faz a partir de uma dupla propriedade: a primeira é constitutiva de sua natureza de ser formada de unidades significantes; a segunda é constitutiva de seu emprego de poder agenciar, arranjar os signos de maneira significante. Benveniste aponta ainda uma terceira propriedade concebida como um elo entre as duas primeiras: a propriedade sintagmática, que diz respeito à propriedade de combinar os signos a partir de certas regras de consecução e somente de certa maneira.

E é na realização dessas propriedades que a língua engloba a sociedade e a contém, instaurando, nessa configuração, o que Benveniste (1989, p. 100) chama de "semantismo social", uma espécie de testemunho que a língua dá sobre as formas de organização social, evidenciado, segundo o autor, principalmente no vocabulário. O semantismo social aponta para o fato de que os signos são capazes de carregar marcas aptas a instaurarem certa referência social, adquirindo valor quando ligados entre si e coordenados a determinada referência instanciada no e pelo uso da língua. Na continuidade de seu raciocínio em Estrutura da língua e estrutura da sociedade, Benveniste se volta à questão que consideramos central na discussão que propomos: "a inclusão do falante em seu discurso, a consideração pragmática que coloca a pessoa na sociedade enquanto participante e que desdobra uma rede complexa de relações espaço-temporais que determinam os modos de enunciação". (BENVENISTE, 1989, p. 101). Esses modos de enunciação, em nossa interpretação, estão relacionados à cultura de uma sociedade particular. E deles nos ocupamos na próxima seção, pois trata-se de um conceito que nos auxiliará a melhor entender os esquemas culturais.

\section{Esquemas culturais: a busca de uma definição}

$\mathrm{Na}$ reflexão apresentada aqui, buscamos situar nosso estudo no escopo da antropologia da enunciação, uma vez que é com este olhar que nos ocupamos da questão dos esquemas culturais; e no universo das relações semiológicas, pois são as relações de significância da língua mobilizadas na particularidade dos discursos que tornam possível tal abordagem. Assim, chegamos à noção de "esquemas culturais", derivada da leitura que fazemos da obra de Benveniste e pautados, principalmente, na afirmação do autor (1989), já mencionada, de que não falamos a língua fora de certos quadros, de certos esquemas. Assim, nesta seção, aproximamo-nos, de uma definição do que estamos entendendo por esquemas culturais. Trata-se, sem dúvida, de um esforço particular de raciocínio e de uma leitura entre tantas que certamente são possíveis nos entremeios das afirmações de Benveniste. Esforçamo-nos, no entanto, para dar à nossa interpretação a clareza e o rigor científico que são exigidos num trabalho desta natureza.

Partimos do fato de que há modos de enunciar revelados na sociedade a partir de determinados esquemas sociais ou culturais. Em DIEDRICH (2017), ao nos voltarmos para a experiência de aquisição da linguagem pela criança, já fomos instigados a pensar sobre a questão e afirmamos que, na experiência de aquisição da linguagem, a criança se apropria de uma língua já existente, a língua do adulto e, por meio dessa apropriação, ela descobre um 
mundo à sua volta. O princípio da abordagem enunciativa aquisicional adotado em Diedrich (2017) nos permite afirmar que:

a criança, ao assumir ou ao ser assumida como alguém que diz, que evoca sentidos, está se historicizando de forma singular, dada a maneira como assume a sua língua e se singulariza por ela. No entanto, traz, em suas enunciações, vestígios da línguadiscurso, do outro, representante da cultura na qual ela está imersa desde antes de seu nascimento. Essa cultura é revelada nos diferentes empregos da língua, (DIEDRICH, 2017, p. 498)

No presente artigo, não estamos discutindo a aquisição da linguagem pela criança, porém acreditamos que a investigação da experiência da criança na linguagem nos ensina não só sobre a criança e a língua, mas também sobre o próprio homem, como uma espécie de flagrante de determinados fenômenos que, passada a infância, parecem não mais se marcarem tão explicitamente na linguagem adulta, embora estejam sempre atuantes. Por essa razão, é nesses raciocínios em torno da aquisição da linguagem que deslocamos alguns princípios que vão nos ajudar a melhor definir a noção de esquemas culturais.

Assim, reafirmamos que a língua se revela no discurso por meio de empregos da língua. Esses empregos em situações enunciativas não são aleatórios ou única e exclusivamente dependentes da vontade do falante. Eles atendem a determinados direcionamentos enunciativos, como as questões vocabulares, os arranjos vocais, entre outros, que revelam a cultura. E, para melhor esclarecermos o que entendemos por cultura, voltamo-nos ao que Benveniste afirma em Vista d'olhos sobre o desenvolvimento da linguística:

A cultura define-se como um conjunto muito complexo de representações, organizadas por um código de relações e de valores: tradições, religião, leis, política, ética, artes, tudo isso de que o homem, onde quer que nasça, será impregnado no mais profundo da sua consciência, e que dirigirá o seu comportamento em todas as formas da sua atividade, o que é senão um universo de símbolos integrados numa estrutura específica e que a linguagem manifesta e transmite? Pela língua, o homem assimila a cultura, a perpetua ou a transforma. (BENVENISTE, 2005, p. 32)

Destacamos, nessa passagem, o fato de que a cultura direciona o comportamento do homem e é manifestada e transmitida pela linguagem. Os esquemas culturais, dessa forma, atuam como direcionadores da atividade enunciativa do locutor, uma vez que não é possível ao locutor enunciar sem tais direcionadores, os quais advêm da relação do homem com sua cultura numa sociedade particular. Essa vivência é característica de todos os homens no mundo, uma vez que todos nascem na cultura de uma sociedade particular e, via linguagem, apreendem esse mundo cultural com todos os seus contornos simbólicos. Ao mesmo tempo, não é uma experiência igual para todos os homens, dada a particularidade de cada vivência, o que acaba por definir a historicidade humana na linguagem. É o simbolismo da língua, o seu poder de significação, que age como "uma semântica que atravessa todos estes elementos de cultura e que os organiza" (BENVENISTE, 2005, p. 25).

Nessa mesma linha, Silva e Oliveira (2016) se voltam para o funcionamento discursivo a partir da investigação da integração do homem à cultura que o cerca, o que atribui à sua 
vida forma, sentido e conteúdo, pois é na relação com o outro, ou seja, via intersubjetividade, que o locutor se funda como sujeito e estabelece a subjetividade, tornando-se capaz de reproduzir discursivamente acontecimentos e experiências, referindo, portanto, e possibilitando ao alocutário recriar pelo seu discurso tais vivências, num processo de correferência, ambos produzindo sentidos a partir de normas e representações sociais, estabelecidas na cultura. Com base em Benveniste, os autores afirmam que, assim como o sistema linguístico, o sistema cultural distingue o que tem e o que não tem sentido, consistindo "numa multidão de noções e de prescrições, e também em interdições específicas; o que uma cultura proíbe a caracteriza tanto quanto aquilo que prescreve" (BENVENISTE, 2005, p. 32).

A discussão proposta por Silva e Oliveira (2016) se relaciona com conceito de esquemas culturais que estamos propondo, a partir do olhar para o movimento realizado pelo locutor entre o domínio semiótico e o domínio semântico: os valores culturais de uma sociedade se marcam nas unidades do domínio semiótico e, na atualização da língua em discurso, esses valores se revelam no domínio semântico em um movimento singular de "adequação ao mundo" (BENVENISTE, 2005, p. 229). Vemos nesse movimento o papel dos esquemas culturais, sempre atrelados a determinados valores já dados pela sociedade, mas, ao mesmo tempo, por estarem impressos nas unidades da língua que se atualizam no discurso, via enunciação, tais esquemas também recebem atualizações particulares no ato de apropriação realizado pelo locutor.

Para Silva e Oliveira (2016, p.409), tal apropriação ou "fabricação" vincula-se à natureza simbólica da linguagem atrelada à propriedade de significação da língua. Os autores, ao olharem para a aquisição da linguagem pela criança, afirmam que esta

\footnotetext{
se instaura nos símbolos de sua cultura através da enunciação, por meio de movimentos de integração entre forma e sentido à medida que descobre que tudo tem um nome, inclusive ela própria, sendo tal descoberta o despertar da consciência do meio social em que vive e que, através da língua, constituirá sua individualidade no interior da coletividade. (SILVA; OLIVEIRA, 2016, p. 409)
}

Temos, assim, o homem se situando em relação à sociedade e à natureza e nesse mover a língua revela o uso particular que os grupos ou classes de homens fazem da língua e as diferenciações que daí resultam no interior da língua comum. Dessons $(2006$, p. 99) afirma que "É pelo exercício da linguagem que os seres humanos se constituem em indivíduos pensantes, capazes de experimentar sua própria coerência, sua identidade". Essa identidade revela a experiência do homem falante na sociedade. Entendemos que "a língua carrega consigo uma série de dados herdados", os quais se organizam em determinados quadros ou esquemas culturais, mobilizados sempre no seio da sociedade. A mobilização da língua na enunciação está relacionada, portanto, à vivência desses esquemas, por meio dos quais se vivencia o que Benveniste chamou de "coincidência": a língua que é assim a emanação do eu mais profundo de cada indivíduo é ao mesmo tempo uma realidade supra-individual e coextensiva a toda coletividade. É esta coincidência entre a língua como realidade objetivável, supra-individual, e a produção individual do falar que fundamenta a relação paradoxal da 
língua com respeito à sociedade (BENVENISTE, 1989, p. 101). Entendemos que é justamente essa relação entre o individual e o social que permite a experiência na linguagem. Assim, ao enunciar, o locutor marca sentidos que estão relacionados às suas emoções, às relações familiares, aos elementos de ordem social, por exemplo, e que determinam os modos de enunciar. No entanto, faz isso sempre de maneira renovada, singularizando-se no aqui-agora de cada enunciação. Isso porque, na relação com o outro, o homem falante está sempre mobilizando sentidos particulares que encontram eco na cultura da sociedade da qual ele faz parte.

Klafke (2016) nos ajuda a compreender essa incursão humana na linguagem. A autora dá destaque para dois diferentes vieses no viver do homem: experiências vividas e experiências não vividas. Isso porque a constituição de nossa linguagem particular se dá nos diversos aqui-agora da enunciação, nos quais mobilizamos as parcelas da língua que acessamos e as transformamos em discurso construído e fundado nas experiências linguísticas que temos ao longo da vida. A autora lembra que mesmo que sejamos expostos a incontáveis experiências linguageiras ou a diferentes variações de referência atribuídas ao semantismo social, nem toda palavra é agregada ao volume constituído por nós como "palavras nossas", pois, para que ingressem em nossa língua-discurso, dependem, em grande parte, da experiência construída na vida social: cada falante tem uma experiência diferente com as palavras.

A mesma autora alerta, no entanto, que, de forma alguma isso torna o semântico totalmente particular, pois particular é apenas a maneira como cada um de nós se relaciona com a língua. Defendemos a proposição de que na vivência de diferentes esquemas sociais e culturais o homem vai constituindo sua própria aventura, na e pela linguagem, que é viver e enunciar de forma particular, mas sempre a partir dos esquemas experienciados. É a intersubjetividade desempenhando seu papel de condição para a subjetividade.

Portanto, vemos, nos esquemas culturais, os valores constitutivos da sociedade humana na cultura organizados e expressos em modos de enunciar, os quais direcionam o movimento de atualização da língua em discurso, vivenciado pelo locutor a cada ato enunciativo. Esses modos de enunciar se dão a conhecer nos arranjos sintagmáticos que marcam a enunciação. Não se trata de apresentar uma definição pronta e acabada, mas de possibilitar, como afirmamos no início deste artigo, uma prospecção teórica do campo da enunciação, o que significa que a discussão apenas se inicia.

Sabedores disso, somos instigados a ilustrar nossa definição de esquemas culturais com uma das manifestações linguageiras mais interessantes da experiência humana: a poética. E o fazemos aqui nas palavras de Mia Couto, poeta moçambicano que fala ao Fronteiras do Pensamento (2013) sobre sua experiência humana na linguagem.

\section{A ilustração do que é um esquema cultural: o caso da manifestação poética}

Transcrevemos, na sequência, num formato bastante funcional, o segmento de fala do poeta Mia Couto ao Fronteiras do Pensamento (2013): 
eu comecei a ter uma relação mais com a poesia... eu pensava... em criança... porque o meu pai era poeta porque o núcleo de gente que acontecia na minha casa ao fim da tarde, à noite, faziam-se, contavam-se histórias, declamavam-se poemas e eu pensava que todo adulto era poeta, portanto, bastava que eu crescesse e automaticamente eu ficaria poeta.

Nesta manifestação sobre sua experiência de linguagem, o poeta deixa claro que há um modo de se relacionar com a língua que o constitui, o poético; e isso se dá em sua vivência de linguagem na relação com o outro, o pai. Vemos, nessa relação, os esquemas culturais se encarregarem de organizar, de um modo muito particular, os arranjos da língua no discurso, os quais marcam a historicidade do homem. Por isso, a partir do que afirma Mia Couto, lembramos a tríade proposta neste artigo: homem - linguagem - cultura, pois a língua, conforme relata o poeta em questão, é produzida e recebida por membros de uma comunidade que compartilham certos valores de referência, que ganham relevância na comunidade em questão. Como se dá tal relevância? Acreditamos que ela se marca na línguadiscurso pelos modos de enunciar reveladores dos esquemas que direcionam a enunciação. $E$ o mais interessante, no caso desta ilustração, é que, no relato de Mia Couto, temos o que Benveniste chama de "tomada de consciência" (1989, p. 28) acerca dos esquemas direcionadores, uma espécie de descoberta do falante em relação ao seu próprio dizer. As palavras de Mia Couto exemplificam bem essa relação de um menino que vive experiências discursivas com o outro de seu convívio social marcadas de modo tão intenso pelo poético que chega ao ponto de pensar que o mundo todo é poesia e que falar é fazer poesia.

Trata-se apenas de uma ilustração do que entendemos ser esquemas culturais e certamente podemos abordar outras tantas manifestações discursivas capazes de revelar outros quadros ou esquemas constitutivos de outros dizeres do homem falante em sua vivência na cultura de uma sociedade. Preferimos fazê-lo via manifestação acerca do poético, porque entendemos ser um modo de enunciar capaz de revelar muito sobre o homem e sua relação com a língua.

\section{Considerações finais}

Por fim, chegamos às seguintes constatações, as quais finalizam essa reflexão no aquiagora deste artigo, embora não sejam um ponto final na busca da elucidação dos esquemas culturais que marcam a manifestação discursiva do homem em sua vivência de linguagem. São as seguintes as nossas constatações:

a) Significar na e pela língua é sempre uma enunciação particular na instância do discurso. Essa particularidade, sem dúvida, se deve principalmente à experiência de linguagem construída pelo homem falante, sempre em relação a outros homens falantes no seio da vida social e cultural. E é ela que garante a singularidade de cada dizer, bem como a historicidade de cada falante construída pela linguagem. 
b) Essa experiência, no entanto, acontece sempre na vida social e cultural, a qual se imprime na língua a partir de esquemas, de quadros que determinam, em grande medida, o vocabulário e os arranjos significantes mobilizados pelo homem falante.

c) Ao enunciar, portanto, o homem não apenas mobiliza formas e sentidos particulares explicitados na língua da qual se apropria, ele mobiliza valores sociais, capazes de revelar muito acerca da sua história construída no seio de uma sociedade e da experiência por ele vivida no mundo que o cerca, os quais direcionam, em certa medida, o seu dizer.

Quiçá nossa experiência de linguagem também possa ir se construindo a partir de esquemas que lembrem, de certa forma, o poético de Mia Couto, pois, conforme Dessons (2011, p. 40), “o 'poema' se apresenta como um discurso em que o sujeito se engaja - ao máximo - na busca do que faz dele um ser de significação".

E é justamente isso que somos: seres de significação, definição que justifica a busca incessante por novos sentidos a partir dos signos dados e conhecidos. Conhecer os esquemas direcionadores de nossa convivência, tal qual o fez Mia Couto, no relato aqui apresentado, é conhecer mais sobre o próprio homem e sobre sua condição de ser de significação.

\section{Referências}

BENVENISTE, É. (1966). Problemas de Linguística Geral I. 5. ed. Campinas: Pontes Editores, 2005.

BENVENISTE, É. (1974). Problemas de Linguística Geral II. 2. ed. Campinas: Pontes Editores, 1989.

COUTO, M. Fronteiras do pensamento. 2013. Vídeo. Disponível em: https://www.youtube.com/watch?v=SHAEgk6TvS. Acesso em: 14 de jan. 2019.

DESSONS, G. Émile Benveniste, l'invention du discours. Paris: Éditions in Press, 2006.

DESSONS, G. Le poème. Paris: Armand Colin, 2011.

DIEDRICH, M. S. Aquisição da linguagem: o aspecto vocal da enunciação na experiência da criança na linguagem. $147 \mathrm{f}$. Tese (Doutorado em Letras) - Programa de Pós-Graduação em Letras, Universidade Federal do Rio Grande Do Sul, Porto Alegre, 2017.

DIEDRICH, M. S. A interpretância da língua em relação às funções inter-humanas do discurso na aquisição da linguagem via aspecto vocal da enunciação. DELTA. Documentação de Estudos em Linguística Teórica e Aplicada, v. 33, p. 497-517, 2017. https://doi.org/10.1590/0102$\underline{445012762971994565}$

FLORES, V. N. A voz como objeto de uma antropologia da enunciação. Working Papers em Linguística, v. 19, n. 2, p. 35-53, 2018. https://doi.org/10.5007/1984-8420.2018v19n2p35

KLAFKE, S. Experimentar(-se) (n)a consciência sobre si mesmo: a ideia da aventura humana na e pela linguagem. ReVEL, edição especial, n. 11, p. 133-146, 2016.

NEUMANN, D. Em busca de uma poética da voz. 2016. 173f. Tese (Doutorado em Letras) Programa de Pós-Graduação em Letras, Universidade Federal do Rio Grande do Sul, Porto Alegre, 2016. 
SILVA, C. L. da C.; OLIVEIRA, G. F. A apropriação de noções culturais pela criança: uma experiência de significação na língua-discurso. Cadernos do IL, Porto Alegre, n. 52, p. 402-420, 2016. https://doi.org/10.22456/2236-6385.67884

SILVA, C. L. da C. A conversão da língua em discurso: enunciar para significar. Antares: Letras e Humanidades, Caxias do Sul, v. 8, n. 15, p. 15-28, 2016.

Recebido em: 15/11/2019. Aceito em: 16/03/2020. 